\title{
Humor - An Aid to Learning and Instruction
}

\author{
Dr. M. Ravichand \\ Associate Professor of English, Sree Vidyanikethan Engineering College, Tirupati
}

\begin{abstract}
If you can make people laugh, you can make them think, make them like and believe you."
Humor represents perhaps one of the most genuine and universal speech acts within human discourse. As a natural consequence then, the employment of humor within the context of second language pedagogy offers significant advantage to both the language teacher and learner. Indeed, humor serves as an effective means of reducing affective barriers to language acquisition. This effectiveness is particularly relevant to the communicative classroom, as humor has been shown to lower the affective filter and stimulate the pro-social behaviors that are so necessary for success within a communicative context. In order to investigate these and other perceived benefits of humor within the language classroom, the researcher of the present study surveyed a diverse collection of language students and teachers and asked them to evaluate the use of humor in their classrooms. Results from this pilot-study strongly confirm a perceived effectiveness for humor as an aid to learning and instruction.
\end{abstract}

\section{Introduction}

Humor is an inextricable part of the human experience and thus a fundamental aspect of humanity's unique capacity for language. In fact, it stands as one of the few universals applicable to all peoples and all languages throughout the world Nevertheless, despite such breadth and scope, humor is rarely discussed among language researchers or educators - perhaps even rarely employed in the classroom on a conscious level.

This paper will argue that such general pedagogical benefits of humor are uniquely suited to the language classroom in general and the dominant contemporary communicative classroom in particular.

This paper, therefore, is intended to stimulate interest in the implications of pedagogical humor in the hope that researchers and teachers alike will recognize the multiplicity of benefits inherent in both general classroom humor as well as the employment of humor for the illustration of specific linguistic and cultural elements of the language.

\section{General Affective Humor}

In light of the minimal attention given to the effects of pedagogical humor by language researchers and educators, any discussion concerning the implications of classroom humor usage must begin within the fields of education and other closely related disciplines of the social sciences. Research foci within these fields have primarily approached the study of humor from within two distinct perspectives. The first of these concerns the direct effects of humor on learning and information retention. That is to say, many researchers have investigated whether humor has a direct effect on saliency of input with a resulting improvement in both information gain and retention. The second perspective examines the possible effects of humor on the general classroom environment and the subsequent indirect correlations such affective factors may have on learning. While both perspectives have yielded researchers important insights into the affective nature of humor on the learning process, it is primarily the latter perspective that has proven itself more fruitful in terms of measurable effect. For this reason, research concerning the indirect effects of humor will serve as the focus here.

Use of humor can reduce tension, disarm aggression, alleviate boredom, and stimulate interest. Among the most commonly stated reasons for employing humor were: its effect as a relaxing, comforting, and tension reducing device, its humanizing effect on teacher image, and its effect of maintaining/increasing student interest and enjoyment. Thus, as Neuliep acknowledges, humor is not perceived as, "a strategy for increasing student comprehension and learning" (p.354). Rather, the indirect and ancillary effects on classroom environment and other affective variables conducive to learning are seen as the result of the employment of humor in the classroom. Similarly, Sudol (1981) claims that humor helps maintain student interest and comfort, while also allowing the teacher an ideal means of diffusing embarrassing situations for both students and the instructor again emphasizing the indirect though beneficial effects of humor on learning. In an analogous manner, Welker (1977) found that humor serves as an "attention getter" and tension reducer, as well as a means for dealing with student and teacher errors in a humane and compassionate manner - remarking, "to err is human, but also, to err is humorous" (p.252). Specifically, Terry and Woods indicate that while too much tension often results in negative affect on learning, too little tension can have similar negative results. Thus, Terry and Woods warn of 
the danger humor presents to an ideal level of tension necessary for learning. In addition, Berwald (1992) suggests that humor must be age appropriate to be beneficially effective, while Zillman and Bryant (1983) caution that humor, particularly sarcastic humor, can confuse students who are not listening carefully or reading non-verbal cues appropriately. Moreover, Sudol (1981) warns that too much humor aimed at a specific individual can be negatively misinterpreted and result in either perceived favoritism or perceived harassment depending on the type of humor employed. Humor, it would seem, is a pedagogical instrument like any other, and one which serves as a double edged sword - capable of improving or harming the classroom learning environment depending on its employment by the teacher.

Despite such possibility of negative effect when improperly employed, humor remains an important instrument for the improvement of educational contexts in general, and language educational contexts in particular. Such beneficial effect is only further emphasized within the contemporary communicative language classroom - which requires significant amounts of language production/experimentation alongside socioconstructivist based interactional components that require high levels of student comfort.

Thus, the evident tension reducing effects of humor, coupled with the creation of an environment conducive to learning through humor-infused immediacy behaviors, suggests the potential for significant positive effect via humor in a communicative context so reliant on such variables for student production and interaction.

Humor offers an ideal avenue for presentation and practice of linguistic mechanics. The following examples illustrate well the effective application of humor to learning structural linguistic components that are typically presented in a rigid and negating manner:

\section{A. Phonology}

Phonological humor ambiguity is created by playing on language sounds, stress, intonation and pronunciation. An example would be the following:
A: How do you make a cat drink?

B: Easy, put it in the liquidizer.

English stress and intonation in "cat drink" above cause the ambiguity, and semantically give it two possible interpretations i.e. a drink for a cat or the way to make a cat drink.

(2) An American in a British hospital asks the nurse: "Did I come here to die?"

The nurse answers, "No, it was yesterdie."

(3) An American asks a Britisher what he does. The Britisher in his ' $r$ '- less vowel dialect responds "I'm a clerk". The American assumes on the basis of this answer that the Britisher sits round all day going "tick, tock, tick, tock".

The ambiguity creating humor here comes from the British pronunciation of the word "clerk" which is understood by the American as "clock".

The phonology example illustrates the ambiguity of pronunciation and dialectical differences between British and American English.

\section{B. Morphology}

Humor can sometimes be created by playing on morphemes as in the following:
A: What's a baby pig called?
B: A piglet.
A: So what's a baby toy called?
B: A toilet.

In the above joke, 'let' is a 'bound morpheme' suffix meaning 'small' as in a 'flat let' meaning a small flat. For the purpose of humor, it is used creatively to make a new word in which the final syllable of 'toilet' is interpreted as the bound morpheme. 'let', hence, creating a new word meaning a small toy. This manipulation of the morphological rule is done on purpose to create this special effect. Another example is the following:

(2) Marriage is a three ring circus:

Engagement ring, wedding ring, and suffering.

Humor here lies in the combination of "suffer" and "ring" which creates the ambiguity. "Ring" may be interpreted as a circular piece of jewellery worn on one's finger for engagement and wedding and it may also be interpreted as a large circular area surrounded by seats in a circus; "suffering" may be seen as a compound word in which "ring" is a free morpheme and is interpreted as a stage that follows engagement and wedding in the three stage marriage process. "suffering", as one word, with "ing" as a bound morpheme, insinuates that marriage ends in physical and mental pain and difficulties . Another example is the following:

$Q$ : Where do you find a birthday present for a cat?

A: In a cat-alogue! 
In the above joke, and for the sake of humor, the word "catalogue" is morphologically divided into two morphemes, "cat", a free morpheme, and (-alogue), a bound morpheme, thereby creating another interpretation i.e., a book with a list of cat goods you can buy from a shop.

\section{Lexicon}

A: "Waiter, do you serve crabs here?" asks a customer.

B: "We serve everybody. Just have a seat at this table, sir."

The lexical item demonstrates the dual meanings of crab (i.e. a cranky person or a marine dwelling crustacean).

\section{Syntax}

Student 1: "The dean announced that he is going to stop drinking on campus."

Student 2: "No kidding! Next thing you know he'll want us to stop drinking too."

The syntax example illustrates the structural ambiguity of the initial sentence - whether the dean is going to stop students' or his own drinking.

\section{E. Syntax + Lexicon}

Q: How do you make a horse fast?

A: Don't give him anything for a while. (Deneire, 1995, pp. 290)

The mixed example of syntax and lexicon demonstrates the ambiguity of the two meanings for fast as well as the employment of fast as a verb or adjective.

All of these jokes may engage and relax students as they simultaneously present and reinforce important elements of the language. Significantly, all of these examples show how instruction of discrete linguistic units can be easily and effectively incorporated into classroom humor usage.

In addition to such formulaic humor, however, original jokes/humor by the instructor can be employed to suit specific classroom circumstances. Moreover, use of puns related to instruction allows for illustration of semantic ambiguity as well as syntax. Take, for example, the following:

One day an English grammar teacher comes to class looking ill.

A student asks, "What's the matter?"

"Tense," the teacher replies in reference to her discomfort.

The student pauses for a moment and then says, "What was the matter? What has been the matter?

What will be the matter...?"

Here, the humor not only displays the ambiguous lexical/semantic properties of the word tense, but also illustrates several grammatical tenses that students would need to identify in order to understand the response.

In order to properly frame the place of humor within such a perspective, one must first acknowledge the tremendous, though often unnoticed, role of humor in daily discourse.

Schmitz (2002) is quick to point out that classroom exposure to humor prepares students to understand and react to this pervasive and authentic element of discourse during real communicative language interactions. Thus, language teachers might incorporate humorous examples/exercises into student role-plays, oral interviews, or written dialogues to acclimate students to the presence of humor in discourse and to demonstrate its patterns of usage. Alternatively, a language instructor might also have students create and incorporate their own humor/jokes into discourse contexts while providing appropriate corrective feedback on humorous usage and style. Significantly, many examples of discourse humor are provided through entirely natural and authentic exchanges of humor between language students and teachers. This, it must be noted, is rarely if ever employed as an explicit pedagogical tool in the mind of the teacher, nor as an explicit learning tool in the mind of the student. Rather, it represents the natural occurrence of humor as a part of the human condition just as it emphasizes its importance to comprehensive language learning.

\section{Conclusions}

The role of pedagogical humor in the language classroom is truly multifaceted and thus requires examination and analysis from a variety of perspectives. Despite some uncertainty concerning the degree to which humor benefits the classroom, the vast majority of literature and experimental evidence in this area has generally acknowledged significant benefits to the pedagogical employment of humor. It is this as yet undefined role for humor in the language classroom that offers perhaps the greatest potential for pedagogical impact. While many language educators may intuitively employ affective humor as a pedagogical tool already, few are likely to employ such targeted linguistic humor in light of its near-total absence from pedagogical training materials. Thus, given the integral part played by humor within all facets of human language, pedagogical researchers and planners have an obligation to its inclusion as both a pedagogical tool and a natural component of linguistic study. The largely supportive perceptions of student and teacher participants in the present pilot 
study only serve as further emphasis for such a need - as well as the impetus for further research in order to clarify the scope of such a requisite.

In sum, humor is a powerful factor in any group situation and has the potential to be used in ways that can make a positive contribution to classroom language learning. Specific goals and objectives must be preestablished and clear in the mind of the teacher. The use of humor may give students another reason to attend class. The fact that they are enjoying it is very rewarding for a teacher. More and more studies today show that humor and laughter have a calming effect on humans and serve to break down the barriers that may exist between people.

\section{References}

[1]. Berwald, J. (1992). Teaching French language and culture by means of humor. The French Review, 66, 189-200.

[2]. Neuliep, J.W. (1991). An examination of the content of high school teacher's humor in the classroom and the development of an inductively derived taxonomy of classroom humor. Communication Education, 40, 343-355.

[3]. Schmitz, J.B. (2002). Humor as a pedagogical tool in foreign language and translation courses. Humor, 15, 89-113.

[4]. Sudol, D. (1981). Dangers of classroom humor. English Journal, 26-28.

[5]. Terry, R. L., \& Woods, M. E. (1975). Effects of humor on the test performance of elementary school children. Psychology in the Schools, 12, 182-185.

[6]. Welker, W. A. (1977). Humor in education: A foundation for wholesome living. College Student Journal, 11, $252-252$.

[7]. Zillman, D., \& Bryant, J. (1983). Uses and effects of humor in educational ventures. In P. E. McGhee \& J. H. Goldstein (Eds.), Handbook of Humor Research, Volume 2 : Applied Studies, 173-194. New York: Springer-Verlag. 